\title{
SOCIAL MEDIA ANALYTICS LENS: A STUDY ON CONSUMER PERCEIVED RISK TO SHARE INFORMATION ON SOCIAL MEDIA NETWORKS Muhammad Ussama Majeed $^{1^{*}}$, Asif Mahmood ${ }^{2}$, Edina Molnar ${ }^{3}$, Shah Ali Murtaza ${ }^{4}$ \\ ${ }^{1 *}$ Institute of Business and Information Technology, University of the Punjab, Lahore, Pakistan; ${ }^{2}$ Department of Business Studies, Namal Institute, Mianwali, Pakistan; ${ }^{3,4}$ Institute of Management and Organizational Sciences, University of Debrecen, Hungary. Email: ${ }^{1 *}$ usamamajeed845@gmail.com, ${ }^{2}$ mahmood.engineer@gmail.com, ${ }^{3}$ molnar.edina.phd@econ.unideb.hu, ${ }^{4}$ shah.ali.murtaza@econ.unideb.hu
} Article History: Received on $21^{\text {st }}$ February 2021, Revised on $1^{\text {st }}$ April 2021, Published on $9^{\text {th }}$ April 2021

\begin{abstract}
Purpose of the study: This study focuses on understanding the potential unfavourable social media analytics practices (SMA) and how they may lead to the negative perception of consumer self-disclosure on social media sites and causing market discomfort for people. We also examined a framework regarding the SMA practices, and their impact on the customer's trust to use social media networks.
\end{abstract}

Methodology: Data were collected from 527 social media users with the help of an online questionnaire. Partial Least Squares Structural equation modeling-PLS-SEM was used using SmartPLS to validate the questionnaire and measure the hypothesized relationships between the constructs.

Main Findings: The results show that perceived risk mediates the relationship between the perceived ethicality of social media analytics and the marketing discomfort of the consumers. Moreover, we also found that the negatively perceived ethicality of social media analytics leads to marketing discomfort of the consumers. This negative attitude impacts the consumer's intention to purchase, interest in the product, and intention to be vulnerable toward the company.

Applications of this study: These findings have practical utility for all types of organizations that use social media. This study is general for all social media sites. This study also provides direction for future research, such as managing the personal information of the social media users from being used by the organizations without consumer permission and developing ethical standards to use the consumer information for the marketing strategies.

Novelty/Originality of this study: Social media analytics (SMA) gathered data from the social media platforms such as Twitter, Instagram, and blogs, representing a massive room to utilize public data, and these lead towards the ethical concerns of the consumers. For this problem, we studied a complete framework to identify the major outcomes of the PESMA on the consumers' self-disclosure and marketing comfort.

Keywords: Ethics, Social Media, Consumer Privacy Management, Social Media Analytics, Marketing Discomfort, Perceived Risk.

\section{INTRODUCTION AND RESEARCH BACKGROUND}

Social Media has influenced how people live, see, and react to things around them. Social media has revolutionized human interaction, especially for businesses and customers. Customers have become more conscious of the market and social media strategies. The market exchange process has also become very receptive to the customers and their choices (Rossolov et al., 2021). Social media has also changed the relationship between the business and the customers, impacting communication between the business and clients; however, it tends to engage the companies with the buyers. It allows the customers to have valuable insight into the company they buy from. (Ma et al., 2021). However, along with the benefits, social media lays massive responsibility on the business to provide authentic information to the customers. Consumers use social media to access the market, generate information, and share it among their friends and social circle via reviews, shares, tweets, and likes (Bailey et al., 2018). With this ever-changing world, organizations are now taking action to adopt strategies related to social media data to enhance and improve their business (Misirlis \& Vlachopoulou, 2018).

The strategies that present a good insight into consumer profiling and consumer likes and dislikes are social media analytics. Gathering the consumer's opinions, consumers demographics, analyzing them, and then using the information to present the consumer-friendly approaches to help the business gain competitive advantage is referred to as social media analytics. (Hajli \& Lin, 2016). Social media analytics (SMA) gathered data from social media sites such as Twitter, Instagram, Snapchat, etc., representing a massive room to utilize public data. It collects information on the new product, presents more personalized offers to customers, and provides information to marketers about the target population's opinion regarding the brand and the company (Jacobson et al., 2020). 
The increased use of social media and the consumer's shared experience of the brands on these platforms has given rise to the "ethical dilemma" as data is gathered without permission from these social media sites (Wieringa et al., 2021). Analytical practices help organizations target a specific audience and make the product more desirable and approachable to the public. But these practices also raise the question of the confidentiality and privacy of social media users, customers, and also the stakeholders as most of the data is drawn without the consent of the user. (Lo et al., 2020)

However, social media use can also impact the consumer that might lead to marketing discomfort. When the public is not comfortable with the marketers' social media approach by using social media data, consumers may develop a negative perception toward the brand and the product and started feeling marketing discomfort (Herrmann, 2020). This negative attitude impacts the consumer's intention to purchase, interest in the product, and intention to be vulnerable toward the company. It also damaged the relationship between the customer and the organization and loss of trust between them (Chinchanachokchai \& de Gregorio, 2020). Self-Disclosure is the phenomenon through which an individual express themselves. It is used in many contextual categories where people give their personal information, likes, and dislikes about any aspect of life. Consumer self-disclosure about themselves has more benefits for companies and organizations as consumers tend to give feedback about the product or become product or brand advocates and opinion leaders (Luo \& Hancock, 2020).

Recent research unravels three painful truths about using social media and personal data; firstly, the structure of the social media business model largely depends on people's data. Secondly, the researcher claims that, somehow, the public permits such stratifying surveillance willingly without knowing the real consequences of it, and lastly, social media is perceived to more effective enablers due to which people rely more on the social media pages. Therefore, it is the need of the hour to address the issues of the accurate and responsible usage of personal information by brands (Flyverbom et al., 2019). In the organizational framework, justice is associated with the organization's ethical practices and the emphasis on fairness and morality. Justice theory lays a good foundation to understand the ethical evaluations of how the information is processed through the organization. Research also focuses on addressing the link between marketing ethics and ethical concerns on the consumers' marketing discomfort with the help of the communication privacy management theory. Therefore, this study aims to understand the potential unfavorable social media analytics practices and how they may lead to the negative perception of self-disclosure and market discomfort. Research questions of the study are as follows:

1. Does perceived risk mediate the relationship between the perceived ethicality of social media analytical practices and self-disclosure?

2. Does perceived risk mediate the relationship between the perceived ethicality of social media analytical practices and marketing discomfort?

3. Does the perceived ethicality of social media analytical practices have a significant relationship with perceived risk?

4. Does the perceived ethicality of social media analytical practices have a significant relationship with consumer selfdisclosure?

5. Does the perceived ethicality of social media analytical practices have a significant relationship with consumer marketing discomfort?

\section{LITERATURE REVIEW}

\section{Social media Marketing}

Social media has changed the perspective of how people live their lives, learn, and connect with others (Zeng \& Gerritsen, 2014). It would not be wrong to say that social media has transformed human life thoroughly. (Andrews et al., 2020). Many organizational and business structures have been changed with social media intervention (Gruzd et al., 2018). In this modern world, social media is used in end-to-end transitions such that the consumers use social media to generate their information and share their experiences with their loved ones. (Dimitriu \& Guesalaga, 2017; Martín-Consuegra et al., 2018). (Zhang \& Zhu, 2021) and ( $\mathrm{Li}$ et al., 2021) found that businesses are taking social media platforms to enhance their sales and adapt to the new virtual strategies to engage customers. Companies widely use the social media platform to target valuable customers by sending personalized offers. Social media platforms have become one of the primary promotional and information hubs for organizations that are certainly interested in understanding what their targeted consumers want and gathering public response for their product (Perčić \& Perić, 2021).

\section{Social media Analytics and Ethical Perception}

Social media analytics is concerned with developing and evaluating the information processing tools to collect, analyze, monitor, and summarize the data gathered from a social media platform to facilitate the organization by providing them with the desired data.(Choi et al., 2020; Kordzadeh \& Young, 2020) Social media analytics helps organizations extract useful 
information relevant to brand promotion and help the organization target a specific audience through social media sites. All of it is combined to make a social media landscape that has become an evident part of the business (Brooker et al., 2016).

Similarly, (Minin et al., 2021) identified that online privacy had become one of the prime concerns of people using social media. Furthermore, social media users consider using their personal information for corporate purposes to breach their privacy and feel concerned about their data. Many people have also labeled such practices as unethical and unjust (Dehghanpouri et al., 2020). In the same way, (Ayaburi \& Treku, 2020) highlighted that such action enrages the public and leading to retaliation of providing information on online forms, boycotting sites that ask for personal information or else providing false information, and registering privacy breaching complaints against the organizations to protect their data from being used in such actions. Consequential ethical and privacy issues are raised when the organizations use the data from social media and the internet more widely to generate capital out of seeking the targeted population. (White \& Boatwright, $\underline{2020)}$

Since the industry is rapidly changing and the competition around the businesses is also growing fiercely, many companies have started to focus on the organizational factors to stay in the competition (Leeflang et al., 2014). One of the critical organizational factors is ethical work climate, as it is used to build long-term relationships with customers. (Wang et al., 2020) in their study of the ethicality of the organization regarding the employee and consumer, had identified that an organization with a proper ethical climate tends to leave a positive mark on the consumer as well as the employee in comparison to the organization with lack the ethicality in them. Similarly, consumers, too, have an ethical perception regarding the organizational framework.

\section{Justice Theory and social media analytics}

Organizations' main goal is to stay in trend and competition with the corporate and business strategy. Therefore, Social media analytical practices are used to maintain the business's status. However, taking the data through social media is still considered unjust (Lopez et al., 2019). On the other hand, justice in organizations holds a significant place as it is regarded as a tool through which organizations function with fairness and ethicality. Hence, any organization's critical structural foundation must be fair and ethical in interacting with consumers (Michaelidou \& Micevski, 2019). Similarly, (Wan et al., 2021) have associated justice with ethicality by focusing on fairness and the organization's morality. The researchers have also highlighted that these moral practices can be exhibited in the company's informational practices and by standing their reputation and fairness in their public dealing.

The Justice theory is very much relevant to the study of social media analytical practices and procedures. These practices are generally considered outside of the organizational-consumer interference and generally carried out in practice without the actual knowledge of the consumer or the social media user's concern of privacy. Therefore, it raises the issues of ethicality (Hajli \& Lin, 2016). In the context of social media analytical practices, the justice theory serves as the necessary foundation of fairness within the organization's procedure through which they collect and analyze data for the business promotion and up-gradation of the organization. However, the linkage of the SMA practices and the organization is also achieved based on the trust between both parties. (Smith et al., 2012). (Michaelidou \& Micevski, 2019) highlighted that SMA context's organizational practices raise psychological concern on the individuals who feel that their privacy concerns have been surpassing by the organization for their material gains.

\section{Communication Privacy Management (CPM)}

Communication Privacy Management (CPM) explains that how people tend to regulate the information they considered private. Typically, the theory aims to explain how people make up their own privacy rules and calculate the amount of the risk or benefits of disclosing information regarding themselves. (Petronio, 2015) Typically, the theory aims to explain how people make up their own privacy rules and calculate the amount of the risk or benefits of disclosing information regarding themselves (Petronio \& Child, 2020). Privacy management is a dialectic approach to privacy concerns. People tend to disclose a certain amount of information to fulfill social needs; however, they tend to conceal certain information about themselves as well. (Baruh et al., 2017). However, CPM has been considered as a fundamental tool to investigate privacy management in the context of social media (Cavusoglu et al., 2016; DeGroot \& Vik, 2017).

The Privacy concern refers to the individuals' belief and it is the predictor of privacy management, including sharing the information online and developing privacy-protecting behaviors such as deleting the cookies and un-tagging the pictures to protect data (Dienlin \& Trepte, 2015) Within the context of social media, online privacy management, and related behaviors are removing one's personal information from a commercial database, deleting cookies, refraining from self-disclosure, or providing false or fabricated information to hide the actual personal data (Bandara et al., 2020) Similarly, privacy management context allows the organization to understand how much the consumer is comfortable when his data is used for marketing purposes. As research has indicated, businesses often overestimate the consumer's comfort of sharing information and the extent to which they feel justified in exchanging their information (Binford et al., 2021). Using the 
privacy management dimensions, an organization can explore the tension between the user's concern for their privacy and the benefits associated with social media (Proudfoot et al., 2018).

\section{Theoretical Framework and Hypothesis}

Compared to the customer-brand relationships and the ethicality of the organization, the social media analytical practice has minimal space in the literature. The social media analytics role is not performed with ethical care. Furthermore, organizations are considered to operate with ethical care, but on the other hand, they are collecting data without consent. It may create a conflict of interest and ethical violations (Podhoranyi, 2021). This study aims to fill the literature gap regarding the ethicality of social media analytical practices and how it harms consumer self-disclosure and marketing discomfort. Justice theory is used to construct the fairness ground regarding the SMA's duties in the organization and using social media information.

H1: Perceived risk positively and significantly mediates the relationship between perceived ethicality of social media analytics and self-disclosure.

H2: Perceived risk positively and significantly mediates the relationship between perceived ethicality of social media analytics and marketing discomfort.

The Communication Privacy Management (CPM) theory was introduced to study consumers revealing and concealing information. The theory explores the regulation of the information that people consider private. This theory aims to describe how humans tend to make their own rule to calculate the perceived cost and benefit analysis to reveal or conceal confidential information (Schyff et al., 2020). It explains how the human tends to estimate the risk and the benefit of disclosing any personal information. The theory further explains that people tend to disclose some of their private information to fulfill the social requirement to be fitted in a while keeping the rest to themselves ( $\mathrm{Hu}$ et al., 2020). Organizations tend to overestimate the consumer's comfort to share their personal information and get overly indulged in their respective information. By applying the CPM theory, we will explore the consumer willingness to disclose themselves, start sharing personal information, and understand the consumer's privacy concerns (Jacobson et al., 2020).

H3: Unfavourable perceived ethicality of SMA has a significant impact on perceived risk to share personal information on social media networks.

The Social Exchange Theory (SET) is generally utilized in the conceptualization of trustworthiness in exchanges, where one party is dependent on the other party's actions. (Carlson et al., 2018) Therefore, trustworthiness actions are considered reciprocal, meaning that the trust has to be returned in the same manner. Moreover, the researchers have established trustworthiness with the concepts of integrity, ability, and beneficence. (Fulmer \& Ostroff, 2017). The present study investigates the impact of the SMA ethical practices on individuals' ability to self-disclose and marketing discomfort. The study's findings will help the marketers provide a safe and trustworthy environment for people who share information publicly on social media and may assist in long-term consumer-brand relationships and provide a safe place for people to share their personal information on social media platforms.

H4: Unfavourable perceived ethicality of SMA has a significant impact on consumer self-disclosure regarding sharing information on social media.

H5: Unfavourable perceived ethicality of SMA has a significant impact on the marketing discomfort of the consumers.

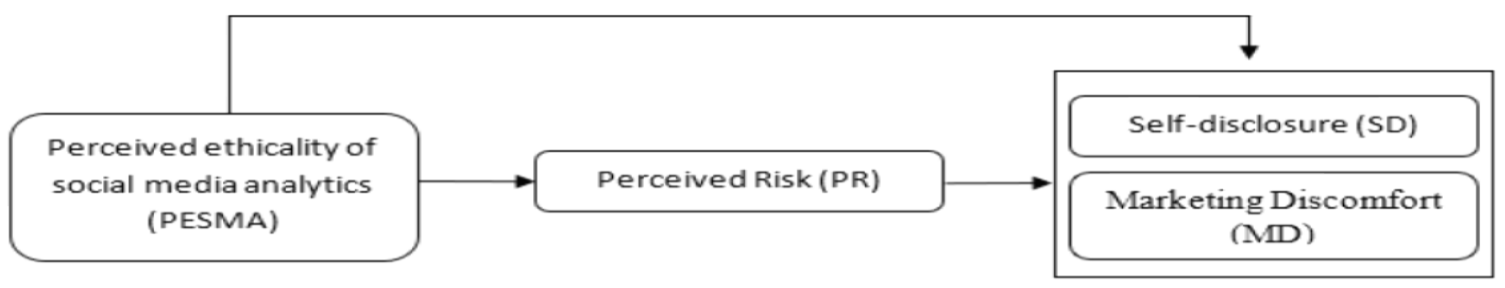

Figure 1: Theoretical Framework

Source: Author's Source 


\section{RESEARCH DESIGN AND DATA ANALYSIS}

\section{Data Collection}

The approach used for the current study is the quantitative research approach. The type of study used is a descriptive study. The researcher's interference was minimum and for the data collection. The present study is purely non-contrived, as the research is based on an online questionnaire and the natural environment without any interruption. This whole study has the "individual unit" of analysis as the data was based on an individual and how they consider the risk associated with social media analytics and how it impacts their willingness to disclose their personal information. Cross-sectional research is used in this study. Therefore, the data is gathered in a single time frame. The nature of the research topic also reflects that data is to be collected in the same time frame, and the data were collected once and not intended to be collected again.

This study population is a group of active social media users and share their information over social media platforms such as Facebook, Instagram, or Twitter. This study includes individuals who have social media accounts. The present study carefully selected the sample to generalize the findings of the study to the whole population. The sample size selected for the current study was about 527. The sample was based on the population of Pakistan that having active social media accounts.

Purposive sampling was chosen for the present study, as the respondents must have active social media users. The data was taken from social media users and was selected based on population and literacy rate. Since the whole country was under lockdown due to the pandemic (COVID 19), it is impossible to physically collect data for the study. Data is collected with the help of self-administrated Google forms. Self-administered questionnaires allow the participants to actually read the question, infer its meaning, and only ask the researcher when facing any confusion in understating the questionnaire.

\section{Demographics}

Demographic profile attributes and characteristics are essential components as they are referenced and explained for helping and facilitating the organizations to take necessary outcomes from the research and generalize the research for some bigger audience. Female respondents are relatively more than male respondents, i.e., 278 females $(52.8 \%)$ and 249 males $(48.2 \%)$. A large portion of the respondents was in the age range of $20-30$ (77.4\%). 36 respondents were nearly younger and fall in the age section of the below 20. There were 60 respondents in the third age bracket, which is 31- 40, making it a sum of $11.4 \%$. About 248 respondents were doing jobs, i.e., employed (47.1\%). The second largest group were students, that consist of 174 respondents (33.0\%). About 233 respondents had 4- 6 accounts on social media. The second-largest group of respondents had 1 - 3 accounts, i.e. $30.2 \%$ of the sample. Almost 118 respondents have $7-10$ accounts on social media sites. Just 17 respondents have above 10 accounts on social media.

Table 1: Respondents Profiles: Gender, Age, No of Social media Accounts

\begin{tabular}{|c|c|c|c|}
\hline & & Frequency & Percentage \\
\hline \multirow[t]{4}{*}{ Gender } & Male & 249 & 47.2 \\
\hline & Female & 278 & 52.8 \\
\hline & Below 20 & 36 & 6.8 \\
\hline & $20-30$ & 408 & 77.4 \\
\hline \multirow[t]{4}{*}{ Age (years) } & $31-40$ & 60 & 11.4 \\
\hline & $41-50$ & 13 & 2.5 \\
\hline & Above 50 & 10 & 1.9 \\
\hline & $1-3$ & 159 & 30.2 \\
\hline \multirow[t]{4}{*}{$\begin{array}{l}\text { No of Social media } \\
\text { Accounts }\end{array}$} & $4-6$ & 233 & 44.2 \\
\hline & $7-10$ & 118 & 22.4 \\
\hline & Above 10 & 17 & 3.2 \\
\hline & $1-3$ & 159 & 30.2 \\
\hline
\end{tabular}

\section{Data Analysis}

After the demographic assessment and solving the data-related issues, SEM-PLS techniques have been selected and adopted in this portion for further assessment of the theoretical framework. SEM is one of the most accurate multivariate tools for testing relationships. It provides the most efficient estimation technique for a series of separate multiple regression equations estimated simultaneously. It has two basic components: (1) the measurement model and (2) the structural model (J. F. Hair et al., 2019).

\section{Measurement model Assessment}

Firstly, in the reflective measurement model, internal consistency reliability and indicator reliability are examined. Internal 
reliability was established by examining the composite reliability. All the values of constructs are fulfilling the condition of the critical level of evaluation. i.e., higher than 0.8 and consist of strong internal consistency reliability.

Table 2: Internal Consistency Reliability

\begin{tabular}{lll}
\hline & Cronbach's Alpha & Composite Reliability \\
\hline PESMA & 0.816 & 0.863 \\
\hline PR & 0.734 & 0.836 \\
\hline SD & 0.844 & 0.892 \\
\hline MD & 0.897 & 0.911 \\
\hline
\end{tabular}

Heterotrait monotrait ratio (HTMT) estimations that are less than 0.9 between the two constructs are viewed as critical about established discriminant validity (Hanafiah, 2020). The HTMT ratio calculation reflects that all the values range from 0.231 to 0.734 . The information that appeared in the HTMT ratio assessment represents significant outcomes as all the values are below 0.9, which is considered the significant level, and discriminant validity is established. Collinearity issues are measured by using the Variance inflation factor (VIF). The tolerance value in PLS-SEM must be above 0.20, if the value is below 0.20, it shows an issue of collinearity. (Munir, 2018). VIF values range from 1.004 to 2.552. So, there is no issue of collinearity.

Table 3: Discriminant Validity - HTMT Ratio

\begin{tabular}{lcccr}
\hline & MD & PESMA & PR & SD \\
\hline MD & & & & \\
\hline PESMA & 0.459 & & & \\
\hline PR & 0.557 & 0.734 & & \\
\hline SD & 0.641 & 0.231 & 0.362 & \\
\hline
\end{tabular}

\section{Significance of Path coefficients}

According to the proposals of (J. Hair et al., 2014) for bootstrapping, the 5000 samples are incorporated. The path coefficient values of the perceived ethicality of social media analytics (PESMA) $\rightarrow$ Perceived risk (PR) is 0.500 , while for PESMA $\rightarrow$ Marketing discomfort (MD) the estimation of the path coefficient is 0.103 . (PESMA) $\rightarrow$ Self-disclosure (SD) has the least value of path coefficient, which is 0.048 . The t values of the constructs are in a range of 1.015 to 13.737. The highest value of $t$ statistics is of the relationship of (PESMA) $\rightarrow$ Perceived risk (PR) 13.737, $t>1$.96. Whereas all the $p$ values of each of the relationships are also significant, i.e. $\mathrm{p}<0.05$, expect (PESMA) $\rightarrow$ Self-disclosure (SD).

Table 4: Significance of Path Coefficients

\begin{tabular}{llllll}
\hline & Original Sample $(\mathbf{O})$ & Mean $(\mathbf{M})$ & Standard Deviation (STDEV) & T Statistics & P Values \\
\hline $\mathrm{PESMA} \rightarrow \mathrm{PR}$ & 0.500 & 0.502 & 0.036 & 13.737 & 0.000 \\
\hline $\mathrm{PESMA} \rightarrow \mathrm{SD}$ & 0.048 & 0.047 & 0.047 & 1.015 & 0.310 \\
\hline PESMA $\rightarrow$ MD & 0.103 & 0.105 & 0.049 & 2.111 & 0.000 \\
\hline
\end{tabular}

The coefficient of determination (R2) value of $0.75,0.50$, or 0.25 for the dependent variable can be depicted as strong, moderate, or weak, respectively. The coefficient of Determination (R2 Value) of the Perceived risk (PR) is 0.658, which is viewed as a substantial impact as it is above 0.5 (moderate impact) and near 0.75 (substantial impact). While self-disclosure (SD) has a low value of 0.250 and consider as a weak effect. Whereas marketing discomfort (MD) has a value of 0.535 and consider a moderate impact. After looking at the R Square Adjusted value, there is no remarkable difference, so we can say that model is parsimonious.

Table 5: Coefficient of Determination $\left(\mathrm{R}^{2}\right.$ Value $)$

\begin{tabular}{lll}
\hline Endogenous Construct & R Square & R Square Adjusted \\
\hline MD & 0.535 & 0.527 \\
\hline SD & 0.250 & 0.249 \\
\hline PR & 0.658 & 0.651 \\
\hline
\end{tabular}

\section{Mediation Analysis}

The indirect effects of this study include the relationship of (1) PESMA $\rightarrow($ PR) $\rightarrow$ SD and (2) PESMA $\rightarrow$ (PR) $\rightarrow$ MD. The path coefficient values of the first relationship (PESMA $\rightarrow(\mathrm{PR}) \rightarrow \mathrm{SD}$ ) is 0.161 , and the t value is significant as of 5.723, i.e., more than the critical level of 1.96 ( $t>1.96$ ). Similarly, the path coefficient values of the second relationship (PESMA $\rightarrow(\mathrm{PR}) \rightarrow \mathrm{MD}$ ) is 0.308 , and the $\mathrm{t}$ value is also significant as of 9.144 that is the highest among both indirect relationships (t $>1.96)$. The $\mathrm{p}$-value of both PESMA $\rightarrow(\mathrm{PR}) \rightarrow \mathrm{SD}$ and PESMA $\rightarrow(\mathrm{PR}) \rightarrow \mathrm{MD}$ is significant at $\mathrm{p}<0.05$. 
Table 6: Total indirect effect

\begin{tabular}{llllll}
\hline & Original Sample (O) & Mean $(\mathbf{M})$ & Standard Deviation (STDEV) & T Statistic & P-Value \\
\hline PESMA -> PR-> SD & 0.161 & 0.163 & 0.028 & 5.723 & 0.000 \\
\hline PESMA -> PR-> MD & 0.308 & 0.310 & 0.034 & 9.144 & 0.000 \\
\hline
\end{tabular}

\section{DISCUSSION}

In this study, we have studied the role of social media analytics and its adverse impact on consumer marketing discomfort and self-disclosure. The current study revealed that perceived risk significantly mediates the relationship between perceived ethicality of social media analytics and marketing discomfort and consumer self-disclosure. These outcomes are consistent with previous studies (Michaelidou \& Micevski, 2019). Michaelidou \& Micevski (2019) penned down that unfavorable social media analytics practices lead to an increase in the perceived risk of the consumer and eventually impact the consumer willingness to disclose about themselves. Similarly, (Jacobson et al., 2020) highlighted that consumers usually evaluate the risk and benefits of sharing information on social media. This trade-off evaluation helps them to understand the potential benefits and risks associated with self-disclosure. Similarly, (Hansen et al., 2018) reflected that consumers could compromise their privacy if they get enough benefits from self-disclosure. The researcher also highlighted that increased perceived risk of data usage by third parties decreased consumer propensity to share information on social media. Moreover, online trust is very critical for organizations as it is the source of online transactions, electronic services, and E-commerce growth. (Lăzăroiu et al., 2020). Similarly (Hajli \& Lin, 2016) have investigated the perceived risk in sharing personal information on SNS and concluded that often fear leakage of information impact consumers' willingness to share their information. These studies also support our results from hypothesis testing, and the mediating role of perceived risk (H1, H2, H3) is supported by the evidence.

Talking about the perceived benefits, social media users somehow understand their data being gathered and analyzed by different organizations for their business purposes. Yet, people willingly disclose their information, searching for the perceived benefit from that data sharing. (Saboo et al., 2016) Moreover, consumers also see the perceived benefit from social media analytics practices, such as they hope that the social media analytics will use the data to cater to the needs of the consumers, a better quality of services (Hoadley et al., 2010). From the previous studies and results from data analysis, we concluded that even the level of the disclosure of personal information depends on the perceived risk analysis of sharing certain personal information by consumers, and the benefits have to outweigh the risk for the consumer to disclose their personal information, i.e., H4 is rejected. Whereas, Marketing ethics refers to the systematic study of how moral standards are applied to marketing decisions and behaviors. (Gonzalez-Padron, 2017) have identified that serious ethical issues are raised by consumers when the organizations attempt to capitalize on the non-consented data from social media. Evidence claim that studies are conducted to understand how marketers make ethical decisions based on their characteristics instead of keeping the consumers in mind. So, H5 is also supported, and we concluded that people's ability to trust the marketers and the marketing discomfort that comes around due to personal data breaching by the organizations is one of the leading factors that consumers become dissatisfied with the marketing approaches.

Table 7: Results of Hypotheses Testing

\begin{tabular}{llll}
\hline Hypotheses & Hypothesized path & Supported & Rejected \\
\hline $\mathrm{H} 1$ & PESMA $\rightarrow \mathrm{PR} \rightarrow \mathrm{SD}$ & $\checkmark$ & \\
\hline $\mathrm{H} 2$ & PESMA $\rightarrow \mathrm{PR} \rightarrow \mathrm{MD}$ & $\checkmark$ & \\
\hline $\mathrm{H} 3$ & PESMA $\rightarrow \mathrm{PR}$ & $\checkmark$ & \\
\hline $\mathrm{H} 4$ & PESMA $\rightarrow \mathrm{SD}$ & & $\checkmark$ \\
\hline $\mathrm{H} 5$ & PESMA $\rightarrow \mathrm{MD}$ & $\checkmark$ & \\
\hline
\end{tabular}

\section{CONCLUSION, RECOMMENDATION, AND LIMITATION}

Social Media can reduce communication costs, increase brand awareness, monitor and respond to the conversation, and target the product's right environment. To gain a more competitive advantage than competitors, the organizations gather data of the target audience to provide better services to the consumers. Social media analytics (SMA) gathered data from the social media platforms such as Twitter, Instagram, and blogs, for targeted marketing. We had studied a complete framework to identify the major outcomes of the PESMA on the consumers' self-disclosure and marketing comfort for this problem. This research had deduced the lack of ethical practices by SMA's, their impact on self-disclosure, and marketing discomfort and provided a framework of the ethical issues that should be taken into concern. For this purpose, data $(\mathrm{n}=527)$ of 527 active social media users were gathered with an online questionnaire. Structural equational modeling was used to determine the relationship between the constructs. In the first phase of data analysis, the reliability and validity of the items were measured. After analyzing the data, we found that unethical practices of Social media analytics lead to marketing discomfort, however, one of our critical outcomes is that perceived risk is facilitating these relationships. i.e., mediation is also proved. 
However, this study is general for all social media sites, but the future recommendation is to research specifically for one platform like Facebook or Twitter as privacy policies for each social media site are different. We also found that the perceived ethicality of social media analytics and the consumer's perceived risk to share information on social media impact consumer self-disclosure. This study also provides direction for future research, such as managing the personal information of the social media users from being used by the organizations without consumer permission and developing ethical standards to use the consumer information for the marketing strategies.

Efforts were made to critically review the literature regarding these variables to develop new concepts, but there is always some space for improvement. In the future, this study can conduct in other countries, including Asia and Europe, so that cross-cultural issues can be resolved. The main focus of the research was consumer perception regarding social media analytics. Therefore, future studies can evaluate past experiences and personal interests while sharing information on social media. Future studies can include the ethical judgment and engagement level on the exposure of social media. Future studies can study the perceived benefits of consumer self-disclosure as our study deduces that people are becoming tolerant to these unethical practices and even know that they have a privacy issue regarding their data. Future studies can also include actions that users can take against the organization or companies using unfavorable social media as these actions are subjective oriented and can vary from one country to another. Future studies can also reflect the advantages that the companies or organizations are achieving by using social media analytics as a powerful weapon. Privacy policies of each of the social media sites vary from one another. In future research must be specific regarding any social media site, like Facebook or Twitter.

There is a certain limitation of this study that must be addressed in future research work. The one-shot or cross-sectional design is one of the limitations of this study as that longitudinal research design was not opted because of the time and cost constraints. While discussing the marketing discomfort, this study had only considered the consumer point of view of the marketing discomfort. This is also a limitation in a broader perspective. This study has not considered any specific social media app while addressing social media analytics. There are differences regarding information privacy management in all the apps.

\section{ACKNOWLEDGMENT}

Special thanks to the faculty members and Head of Institute of Business and Information Technology, University of the Punjab, Lahore, Pakistan.

\section{AUTHORS CONTRIBUTION}

Muhammad Ussama Majeed presented this idea. Ussama also has a major contribution to this article by facilitating literature, identifying gaps, and analyzing the portion of the paper. Shah Ali Murtaza contributed to the theoretical framework, grounded theories, and research implication. Asif Mahmood and Edina Molnar, as senior researchers, supervised all the tasks and help in interpretation, future direction, and research structure.

\section{REFERENCES}

1. Andrews, N. P., Yogeeswaran, K., Wang, M.-J., Nash, K., Hawi, D. R., \& Sibley, C. G. (2020). Is Social Media Use Changing Who We Are? Examining the Bidirectional Relationship Between Personality and Social Media Use. Cyberpsychology, Behavior, and Social Networking, 23(11), 752-760. https://doi.org/10.1089/cyber.2019.0744

2. Ayaburi, E. W., \& Treku, D. N. (2020). Effect of penitence on social media trust and privacy concerns: The case of Facebook. International Journal of Information Management, 50, 171-181. https://doi.org/10.1016/j.ij infomgt.2019.05.014

3. Bailey, A. A., Bonifield, C. M., \& Arias, A. (2018). Social media use by young Latin American consumers: An exploration. Journal of Retailing and Consumer Services, 43, 10-19. https://doi.org/10.1016/j.jretconser. 2018.02.003

4. Bandara, R., Fernando, M., \& Akter, S. (2020). Managing consumer privacy concerns and defensive behaviours in the digital marketplace. European Journal of Marketing, 55(1), 219-246. https://doi.org/10.1108/EJM-06-2019$\underline{0515}$

5. Baruh, L., Secinti, E., \& Cemalcilar, Z. (2017). Online Privacy Concerns and Privacy Management: A MetaAnalytical Review. Journal of Communication, 67(1), 26-53. https://doi.org/10.1111/jcom.12276

6. Binford, M. T., Wojdynski, B. W., Lee, Y.-I., Sun, S., \& Briscoe, A. (2021). Invisible transparency: Visual attention to disclosures and source recognition in Facebook political advertising. Journal of Information Technology \& Politics, 18(1), 70-83. https://doi.org/10.1080/19331681.2020.1805388

7. Brooker, P., Barnett, J., \& Cribbin, T. (2016). Doing social media analytics. Big Data \& Society, 3(2), 2053951716658060. https://doi.org/10.1177/2053951716658060 
8. Carlson, J., Rahman, M., Voola, R., \& De Vries, N. (2018). Customer engagement behaviors in social media: Capturing innovation opportunities. Journal of Services Marketing, 32(1), 83-94. https://doi.org/10.1108/JSM-022017-0059

9. Cavusoglu, H., Phan, T. Q., Cavusoglu, H., \& Airoldi, E. M. (2016). Assessing the Impact of Granular Privacy Controls on Content Sharing and Disclosure on Facebook. Information Systems Research, 27(4), 848-879. https://doi.org/10.1287/isre.2016.0672

10. Chinchanachokchai, S., \& de Gregorio, F. (2020). A consumer socialization approach to understanding advertising avoidance on social media. Journal of Business Research, 110, 474-483. https://doi.org/10.1016/j.jbusres. 2020.01.062

11. Choi, J., Yoon, J., Chung, J., Coh, B.-Y., \& Lee, J.-M. (2020). Social media analytics and business intelligence research: A systematic review. Information Processing \& Management, 57(6), 102279. https://doi.org/10.1016 /j.ipm.2020.102279

12. DeGroot, J. M., \& Vik, T. A. (2017). We were not prepared to tell people yet. Computers in Human Behavior, 70(C), 351-359. https://doi.org/10.1016/j.chb.2017.01.016

13. Dehghanpouri, H., Soltani, Z., \& Rostamzadeh, R. (2020). The impact of trust, privacy, and quality of service on the success of E-CRM: The mediating role of customer satisfaction. Journal of Business \& Industrial Marketing, 35(11), 1831-1847. https://doi.org/10.1108/JBIM-07-2019-0325

14. Dienlin, T., \& Trepte, S. (2015). Is the privacy paradox a relic of the past? An in-depth analysis of privacy attitudes and privacy behaviors. European Journal of Social Psychology, 45(3), 285-297. https://doi.org/10.1002/ejsp.2049

15. Dimitriu, R., \& Guesalaga, R. (2017). Consumers' Social Media Brand Behaviors: Uncovering Underlying Motivators and Deriving Meaningful Consumer Segments. Psychology \& Marketing, 34(5), 580-592. https://doi.org/10.1002/mar.21007

16. Flyverbom, M., Deibert, R., \& Matten, D. (2019). The Governance of Digital Technology, Big Data, and the Internet: New Roles and Responsibilities for Business. Business \& Society, 58(1), 3-19. https://doi.org/10.1177/0007650317727540

17. Fulmer, C. A., \& Ostroff, C. (2017). Trust indirect leaders and top leaders: A trickle-up model. Journal of Applied Psychology, 102(4), 648-657. https://doi.org/10.1037/apl0000189

18. Gonzalez-Padron, T. L. (2017). Ethics in the Sharing Economy: Creating a Legitimate Marketing Channel. Journal of Marketing Channels, 24(1-2), 84-96. https://doi.org/10.1080/1046669X.2017.1347005

19. Gruzd, A., Jacobson, J., Mai, P., \& Dubois, E. (2018). Social Media Privacy in Canada (SSRN Scholarly Paper ID 3195503). Social Science Research Network. https://doi.org/10.2139/ssrn.3195503

20. Hair, J. F., Risher, J. J., Sarstedt, M., \& Ringle, C. M. (2019). When to use and how to report the results of PLSSEM. European Business Review, 31(1), 2-24. https://doi.org/10.1108/EBR-11-2018-0203

21. Hair, J., Hult, G. T. M., Ringle, C., \& Sarstedt, M. (2014). A Primer on Partial Least Squares Structural Equation Modeling.

22. Hajli, N., \& Lin, X. (2016). Exploring the Security of Information Sharing on Social Networking Sites: The Role of Perceived Control of Information. Journal of Business Ethics, 133(1), 111-123. https://doi.org/10.1007/s10551014-2346-X

23. Hanafiah, M. H. (2020). Formative Vs. Reflective Measurement Model: Guidelines for Structural Equation Modeling Research. International Journal of Analysis and Applications, 18(5), 876-889. https://doi.org/10.28924/2291-8639

24. Hansen, J. M., Saridakis, G., \& Benson, V. (2018). Risk, trust, and the interaction of perceived ease of use and behavioral control in predicting consumers' use of social media for transactions. Computers in Human Behavior, 80, 197-206. https://doi.org/10.1016/j.chb.2017.11.010

25. Herrmann, A. F. (2020). The Routledge International Handbook of Organizational Autoethnography. Routledge.

26. Hoadley, C. M., Xu, H., Lee, J. J., \& Rosson, M. B. (2010). Privacy as information access and illusory control: The case of the Facebook News Feed privacy outcry. Electronic Commerce Research and Applications, 9(1), 50-60. https://doi.org/10.1016/j.elerap.2009.05.001

27. Hu, M., Momot, R., \& Wang, J. (2020). Privacy Management in Service Systems (SSRN Scholarly Paper ID 3628751). Social Science Research Network. https://doi.org/10.2139/ssrn.3628751

28. Jacobson, J., Gruzd, A., \& Hernández-García, Á. (2020). Social media marketing: Who is watching the watchers? Journal of Retailing and Consumer Services, 53, 101774. https://doi.org/10.1016/j.jretconser.2019.03.001

29. Kordzadeh, N., \& Young, D. K. (2020). How Social Media Analytics Can Inform Content Strategies. Journal of Computer Information Systems, O(0), 1-13. https://doi.org/10.1080/08874417.2020.1736691

30. Lăzăroiu, G., Neguriță, O., Grecu, I., Grecu, G., \& Mitran, P. C. (2020). Consumers’ Decision-Making Process on Social Commerce Platforms: Online Trust, Perceived Risk, and Purchase Intentions. Frontiers in Psychology, 11. https://doi.org/10.3389/fpsyg.2020.00890 
31. Leeflang, P. S. H., Verhoef, P. C., Dahlström, P., \& Freundt, T. (2014). Challenges and solutions for marketing in a digital era. European Management Journal, 32(1), 1-12. https://doi.org/10.1016/j.emj.2013.12.001

32. Li, F., Larimo, J., \& Leonidou, L. C. (2021). Social media marketing strategy: Definition, conceptualization, taxonomy, validation, and future agenda. Journal of the Academy of Marketing Science, 49(1), 51-70. https://doi.org/10.1007/s11747-020-00733-3

33. Lo, L. W. T., Chan, H., Tang, F., \& Yeung, K.-Y. (2020). Consumer ethics: Insights from business professionals. Asia Pacific Journal of Marketing and Logistics, 32(3), 664-680. https://doi.org/10.1108/APJML-07-2018-0273

34. Lopez, B. E., Magliocca, N. R., \& Crooks, A. T. (2019). Challenges and Opportunities of Social Media Data for Socio-Environmental Systems Research. Land, 8(7), 107. https://doi.org/10.3390/land8070107

35. Luo, M., \& Hancock, J. T. (2020). Self-disclosure and social media: Motivations, mechanisms and psychological well-being. Current Opinion in Psychology, 31, 110-115. https://doi.org/10.1016/j.copsyc.2019.08.019

36. Ma, L., Zhang, X., Ding, X., \& Wang, G. (2021). How Social Ties Influence Customers' Involvement and Online Purchase Intentions. Journal of Theoretical and Applied Electronic Commerce Research, 16(3), 395-408. https://doi.org/10.3390/jtaer16030025

37. Martín-Consuegra, D., Faraoni, M., Díaz, E., \& Ranfagni, S. (2018). Exploring relationships among brand credibility, purchase intention and social media for fashion brands: A conditional mediation model. Journal of Global Fashion Marketing, 9(3), 237-251. https://doi.org/10.1080/20932685.2018.1461020

38. Michaelidou, N., \& Micevski, M. (2019). Consumers' ethical perceptions of social media analytics practices: Risks, benefits, and potential outcomes. Journal of Business Research, 104, 576-586. https://doi.org/10.1016/j.jb usres.2018.12.008

39. Minin, E. D., Fink, C., Hausmann, A., Kremer, J., \& Kulkarni, R. (2021). How to address data privacy concerns when using social media data in conservation science. Conservation Biology, 35(2), 437-446. https://doi.org /10.1111/cobi.13708

40. Misirlis, N., \& Vlachopoulou, M. (2018). Social media metrics and analytics in marketing - S3M: A mapping literature review. International Journal of Information Management, 38(1), 270-276. https://doi.org/10.1016 /j.ijinfomgt.2017.10.005

41. Munir, F. F. A. (2018). Reliability and Validity Analysis on the Relationship between Learning Space, Student's Satisfaction and Perceived Performance Using SMART-PLS. https://doi.org/10.6007/IJARBSS/V8-I1/3847

42. Perčić, K., \& Perić, N. (2021). The Effectiveness of Direct Marketing Media Regarding Attitudes of Different Target Groups of Consumers in Serbia. Periodica Polytechnica Social and Management Sciences, 29(1), 21-32. https://doi.org/10.3311/PPso.13616

43. Petronio, S. (2015). Communication Privacy Management Theory. In The International Encyclopedia of Interpersonal Communication (pp. 1-9). American Cancer Society. https://doi.org/10.1002/9781118540190.wbeic132

44. Petronio, S., \& Child, J. T. (2020). Conceptualization and operationalization: Utility of communication privacy management theory. Current Opinion in Psychology, 31, 76-82. https://doi.org/10.1016/j.copsyc.2019.08.009

45. Podhoranyi, M. (2021). A comprehensive social media data processing and analytics architecture by using big data platforms: A case study of Twitter flood-risk messages. Earth Science Informatics. https://doi.org/10.1007/s12145021-00601-W

46. Proudfoot, J. G., Wilson, D., Valacich, J. S., \& Byrd, M. D. (2018). Saving face on Facebook: Privacy concerns, social benefits, and impression management. Behaviour \& Information Technology, 37(1), 16-37. https://doi.org/10.1080/0144929X.2017.1389988

47. Rossolov, A., Rossolova, H., \& Holguín-Veras, J. (2021). Online and in-store purchase behavior: Shopping channel choice in a developing economy. Transportation. https://doi.org/10.1007/s11116-020-10163-3

48. Saboo, A. R., Kumar, V., \& Ramani, G. (2016). Evaluating the impact of social media activities on human brand sales. International Journal of Research in Marketing, 33(3), 524-541. https://ideas.repec.org/a/eee/ijrema/v33 y2016i3p524-541.html

49. Schyff, K. van der, Flowerday, S., \& Furnell, S. (2020). Duplicitous social media and data surveillance: An evaluation of privacy risk. Computers \& Security, 94, 101822. https://doi.org/10.1016/j.cose.2020.101822

50. Smith, A. N., Fischer, E., \& Yongjian, C. (2012). How Does Brand-related User-generated Content Differ across YouTube, Facebook, and Twitter? Journal of Interactive Marketing, 26(2), 102-113. https://doi.org/10.1 016/j.intmar.2012.01.002

51. Wan, J., Lu, Y., \& Gupta, S. (2021). The dashing feature in social media: A personality and justice theory perspective. Information Technology \& People, ahead-of-print(ahead-of-print). https://doi.org/10.1108/ITP-08$\underline{2018-0389}$ 
52. Wang, X., Tajvidi, M., Lin, X., \& Hajli, N. (2020). Towards an Ethical and Trustworthy Social Commerce Community for Brand Value Co-creation: A Trust-Commitment Perspective. Journal of Business Ethics, 167(1), 137-152. https://doi.org/10.1007/s10551-019-04182-Z

53. White, C. L., \& Boatwright, B. (2020). Social media ethics in the data economy: Issues of social responsibility for using Facebook for public relations. Public Relations Review, 46(5), 101980. https://doi.org/10.1016/j.pubrev.2020.101980

54. Wieringa, J., Kannan, P. K., Ma, X., Reutterer, T., Risselada, H., \& Skiera, B. (2021). Data analytics in a privacyconcerned world. Journal of Business Research, 122, 915-925. https://doi.org/10.1016/j.jbusres.2019.05.005

55. Zeng, B., \& Gerritsen, R. (2014). What do we know about social media in tourism? A review. Tourism Management Perspectives, 10, 27-36. https://doi.org/10.1016/j.tmp.2014.01.001

56. Zhang, F., \& Zhu, L. (2021). Promoting business model innovation through social media strategic capability: A moderated mediation model. European Management Journal. https://doi.org/10.1016/j.emj.2021.02.003 